\title{
Aclidinium inhibits proliferation and metastasis of ovarian cancer SKOV3 cells via downregulating PI3K/AKT/mTOR signaling pathway
}

\author{
JUAN QIAO $^{1}$, WEI-JING WANG ${ }^{2}$ and YUAN ZHANG ${ }^{3}$ \\ ${ }^{1}$ Department of Obstetrics and Gynecology, The First Affiliated Hospital of Chongqing Medical University, \\ Chongqing 400010; ${ }^{2}$ Gynecology Department Five of The Harbin Red Cross Center Hospital, \\ Harbin, Heilongjiang 150076; ${ }^{3}$ Department of Gynecology and Obstetrics, The Second Affiliated \\ Hospital of Hainan Medical University, Haikou, Hainan 570203, P.R. China
}

Received May 22, 2018; Accepted September 12, 2018

DOI: $10.3892 / \mathrm{ol} .2018 .9460$

\begin{abstract}
Aclidinium, a muscarinic antagonist, is generally used to treat the respiratory system diseases whereas it is not clear whether aclidinium has therapeutic effect in ovarian cancer (OC). The aim of this study was to investigate the impact of aclidinium on $\mathrm{OC}$ and its potential mechanism. CCK-8 was employed to test the potential effect of aclidinium on SKOV3 cell proliferation. Transwell migration and invasion assay was performed to assess the influence of aclidinium on SKOV3 cell metastasis and invasion. Furthermore, flow cytometry apoptotic analysis was used to evaluate the effect of aclidinium on cell apoptosis. Finally, western blotting was applied to determine the changes of key proteins in apoptosis and PI3K/AKT/mTOR signaling pathway induced by aclidinium. The study showed that aclidinium had antiproliferative activity on SKOV3 cells. Simultaneously, aclidinium could significantly inhibit the number of migrated and invaded SKOV3 cells and markedly increased the SKOV3 cell apoptosis rate. Mechanistically, the expression of PI3K/AKT/mTOR signaling pathway related proteins were significantly inhibited in aclidinium treated SKOV3 cells. Our findings proposed a clue for further OC studies in preclinical and clinical treatment and aclidinium may be useful for the treatment of $\mathrm{OC}$ in the future.
\end{abstract}

\section{Introduction}

Ovarian cancer (OC) is ranked fifth among adults worldwide while it is the most deadly gynecological disease $(1,2)$. The

Correspondence to: Dr Yuan Zhang, Department of Gynecology and Obstetrics, The Second Affiliated Hospital of Hainan Medical University, 10 Haifu Road, Haikou, Hainan 570203, P.R. China E-mail: 13016231168@163.com

Key words: ovarian cancer, aclidinium, PI3K/AKT/mTOR signaling pathway, proliferation incidence of OC has shown an increasing trend in China, over 50,000 new cases and the death toll exceeded 20,000 in 2015 (3). The current standard treatment for OC is surgery and adjuvant chemotherapy with platinum and taxane (4). Although many women with epithelial OC incipiently respond to this regimen, the recurrence rate is high, and the survival rate is less than $50 \%$ (5). Due to the frequently-occurring side effect of the present chemotherapy, it is urgent to find novel drugs for OC treatment (6).

A large proportion of cancers derive from epithelial and endothelial cells have been reported to express muscarinic acetylcholine receptors (mAChR), activation of which leads to increase cell proliferation (7). It has previously been reported that activation of muscarinic (mAChRs) can promote the growth of tumor cells in colon, lung, glial cells and prostate (8). Simultaneously, the presence of mAChRs receptors in ovarian tumor has been confirmed, and expression of $\mathrm{mAChRs}$ receptor relates with worse prognosis in ovarian SKOV3 cancer (9). Conversely, antimuscarinic drug potentially represses cancer cells growth (10). Song et al found that M3 muscarinic receptor antagonist could impede the proliferation of lung cancer cells (11). In line with this report, the presence of muscarinic receptors in $\mathrm{OC}$ is correlated with reduced patient survival (9). Therefore, using muscarinic antagonist might be promising for OC treatment.

Aclidinium (N-methyl-quinuclidinyl-benzylate), which is commonly used to treat respiratory system diseases (12), is a typical muscarinic M3 antagonist. Aclidinium has superiority of slightly quicker onset of action and favorable safety profile with low toxicity. Yet, it is rarely reported in the treatment of cancer, especially OC prognosis. Here, using western blotting, Cell Counting Kit-8 (CCK-8) proliferation assay, Transwell metastasis, invasion assay and apoptosis flow assay, we found the inhibitory effects and underlying mechanism of aclidinium on OC growth.

\section{Materials and methods}

Cell culture. The normal human OC line SKOV3 was provided from the Type Culture Collection of the Chinese Academy of 
Sciences (Shanghai, China). Cells were routinely cultivated in RPMI-1640 medium (Gibco; Thermo Fisher Scientific, Inc., Waltham, MA, USA) with supplemented with $10 \%$ fetal bovine serum (FBS), containing penicillin $(100 \mathrm{U} / \mathrm{ml})$ and streptomycin $(100 \mu \mathrm{g} / \mathrm{ml})$ at $37^{\circ} \mathrm{C}$ in $5 \% \mathrm{CO}_{2}$ humidified atmosphere. Cells in exponential growth phase $\left(\sim 1 \times 10^{6}\right.$ cells $\left./ \mathrm{ml}\right)$ were used for the following experiment.

Cell proliferation assay. Proliferation of cells was tested by CCK-8 in accordance with the manufacturer's instructions. Approximately $5 \times 10^{3}$ cells were seeded in a 96-well plate. After overnight culture, experimental group cells administered with $20 \mu \mathrm{M}$ aclidinium (MCE Corporation, Dublin, CA, USA) and control groups (NC) cells containing $1 \%$ DMSO (Amresco, LLC, Solon, OH, USA) in culture media were cultured for $72 \mathrm{~h}$, and then $10 \mu \mathrm{l}$ CCK- 8 reagent (Solai Po Company, Beijing, China) was added to each well. Then the plates were incubated for $1.5 \mathrm{~h}$ at $37^{\circ} \mathrm{C}$. The cell viability was measured every $24 \mathrm{~h}$. CCK-8 detection steps were the same as above. Absorbance value [optical density (OD)] was tested at $450 \mathrm{~nm}$ by a microplate reader (Bio-Rad, Hercules, CA, USA).

Transwell metastasis and invasion assay. Migration and invasion tests were executed using 24-well Transwell chambers (EMD Millipore, Billerica, MA, USA) with membrane pore size of $8.0 \mu \mathrm{M}$ and without/with Matrigel (both from BD Biosciences, San Jose, CA, USA) following the manufacturer's instructions. A total of $100 \mu \mathrm{l}$ cell suspensions $\left(\sim 1 \times 10^{5}\right)$ were seeded to upper chamber, whereas $500 \mu 1$ culture medium containing with $10 \%$ FBS filled the lower chamber. After incubation overnight at $37^{\circ} \mathrm{C}, 5 \% \mathrm{CO}_{2}$, cotton-tipped swabs were used to scrape off the non-migrating cells on the top chamber and then cells migrated through the membrane were fixed with $4 \%$ paraformaldehyde for $30 \mathrm{~min}$. They were dyed with $0.1 \%$ crystal violet for $20 \mathrm{~min}$. The migrated cells in the bottom of the chamber were randomly selected for five visual field and were counted under a microscope. For cell invasion detection, the steps were similar to detection of cells metastasis except the Matrigel was plated in the Transwell inserts.

Flow cytometry apoptosis assay. Apoptotic SKOV3 cells were analyzed by an Annexin V-fluorescein isothiocyanate (Annexin V-FITC)/propidium iodide (PI) apoptosis detection kit (Beijing 4A Biotech, Co., Ltd., Beijing, China) according to the manufacturer's instructions. SKOV3 cells were treated with aclidinium and harvested by trypsinization without EDTA. Then, they were rinsed twice with cold PBS, centrifuged at $1111 \mathrm{x} \mathrm{g}$ at room temperature for $5 \mathrm{~min}$ and the supernatant was removed, the pellet was resuspended in $500 \mu \mathrm{l} 1 \mathrm{X}$ binding buffer, and the cell density were adjusted to $3 \times 10^{6}$ cells $/ \mathrm{ml}$. Then, FITC-conjugated Annexin V and PI were added. After incubation for $5 \mathrm{~min}$ in the dark at room temperature, flow cytometry was acquired on a FACSCalibur (BD Biosciences) and analyzed using Flowjo 7.6 software (Tree Star, Ashland, OR, USA).

Western blot analysis. After treatment with aclidinium or vehicle for $24 \mathrm{~h}$, the cells were added with RIPA lysis buffer (CWBIO, Beijing, China) for the cleavage and extraction

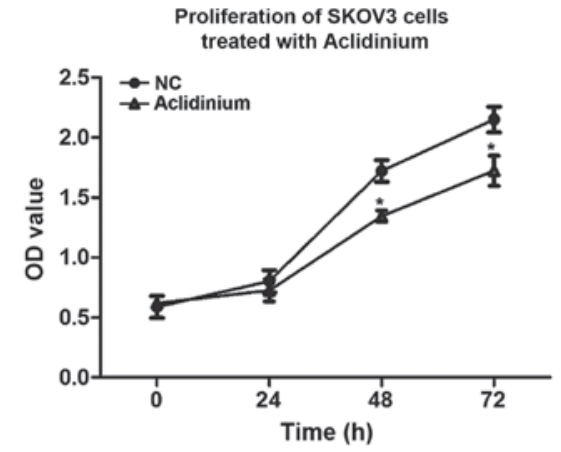

Figure 1. Aclidinium inhibits proliferation of ovarian cancer SKOV3 cells. Cell viability was tested by CCK-8 proliferation assay for $72 \mathrm{~h}$ in SKOV3 cells. Data are expressed as mean $\pm \mathrm{SD}$. ${ }^{*} \mathrm{P}<0.05$, on comparing NC group. CCK-8, Cell Counting Kit-8.

of protein. Proteins concentrations were analyzed by BCA protein assay kit (CWBIO). Proteins with equal amount $20 \mu \mathrm{g}$ were separated on $8-10 \%$ Tris-glycine gradient gels via dodecyl sulfate-polyacrylamide gel electrophoresis. Then these proteins were tranferred onto PVDF membrane for $2 \mathrm{~h}$ and blocked with 5\% non-fat milk in TBST buffer $(\mathrm{pH} 7.4$ Tris-buffered saline buffer containing $0.1 \%$ Tween-20) for $1 \mathrm{~h}$ at room temperature. Next, membranes were probed with primary antibodies including AKT (cat. no. 4691), p-AKT (cat. no. 4060), mTOR (cat. no. 2972), p-mTOR (cat. no. 2974) at 1:1,000 dilution (Cell Signaling Technology, Inc., Danvers, MA, USA); Bcl-2 (cat. no. 12789-1-AP), Bax (cat. no. 50599-2-Ig), active-caspase-3 (cat. no. 19677-1-AP), cyclin D1 (cat. no. 60186-1-Ig), P-70 (cat. no. 14485-1-AP) at 1:1,000 dilution (ProteinTech Group, Inc., Wuhan, China); tubulin at 1:5,000 dilution (ProteinTech Group, Inc.) overnight in $4^{\circ} \mathrm{C}$ at room temperature, and were detected using antirabbit (cat. no. 66467-1-Ig)/mouse (cat. no. 10283-1-AP) horseradish peroxidase-conjugated secondary antibodies (PTG 1:5,000). Primary and secondary antibodies are from Sigma-Aldrich; Merck KGaA (Darmstadt, Germany). Protein expression was visualized using a chemiluminescence reagent (ECL) system (PTG, Chicago, IL, USA). Protein bands were analyzed by measuring densitometry using Image J 6.0 software (National Institutes of Health (NIH), Stapleton, NY, USA) and quantitative densitometry of bands were expressed by bar charts.

Statistical analysis. Statistical analysis was carried out by using SPSS18.0 (SPSS, Inc., Chicago, IL, USA) and GraphPad Prism 5 software (GraphPad Software, Inc., La Jolla, CA, USA). The measurement data are the mean \pm standard deviation (SD). The Student's t test was performed to compare the mean between two samples. $\mathrm{P}<0.05$ was considered to indicate a statistically significant difference.

\section{Results}

Aclidinium inhibits the proliferation of OC SKOV3 cells. To investigate the influence of aclidinium on SKOV3 cell proliferation, CCK-8 was used to analyze cell viability in vitro. We observed that prohibitive action on SKOV3 cells after treatment with aclidinium was in an obvious time-dependent mode and 

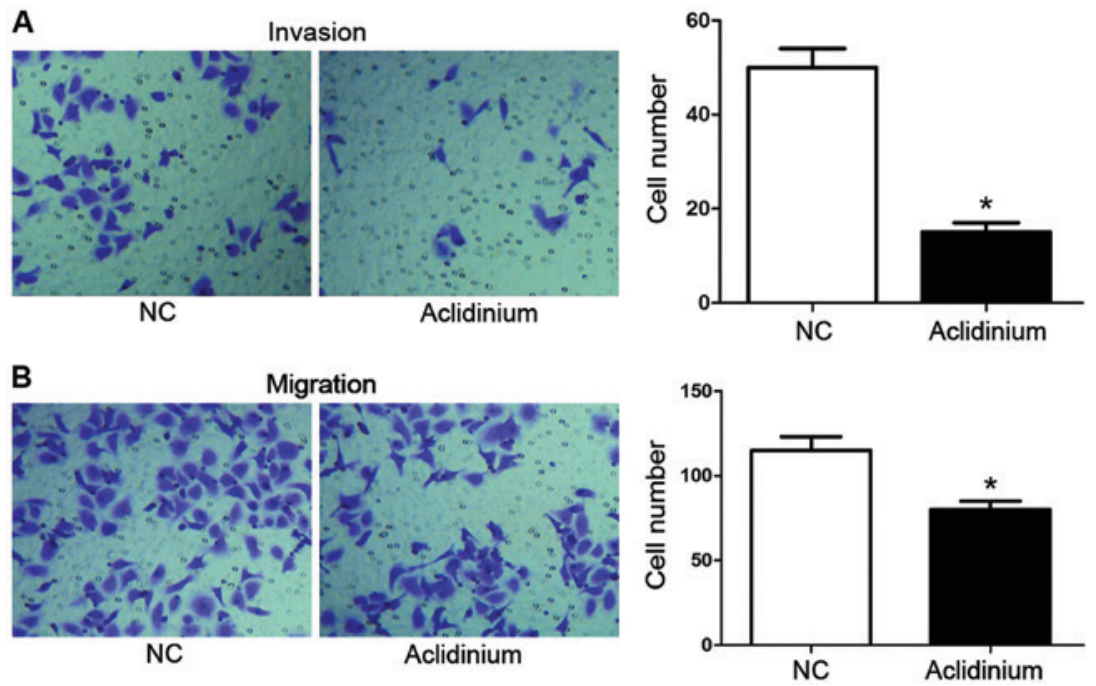

Figure 2. Aclidinium inhibits invasion of ovarian cancer SKOV3 cells. Cell invasion ability was measured by Transwell assay. Representative images of crystal violet stained invasive cells. (A) Invaded number of SKOV3 cell was measured. (B) Migrated number of SKOV3 cells was measured. "P<0.05, in contrast with NC group.

A
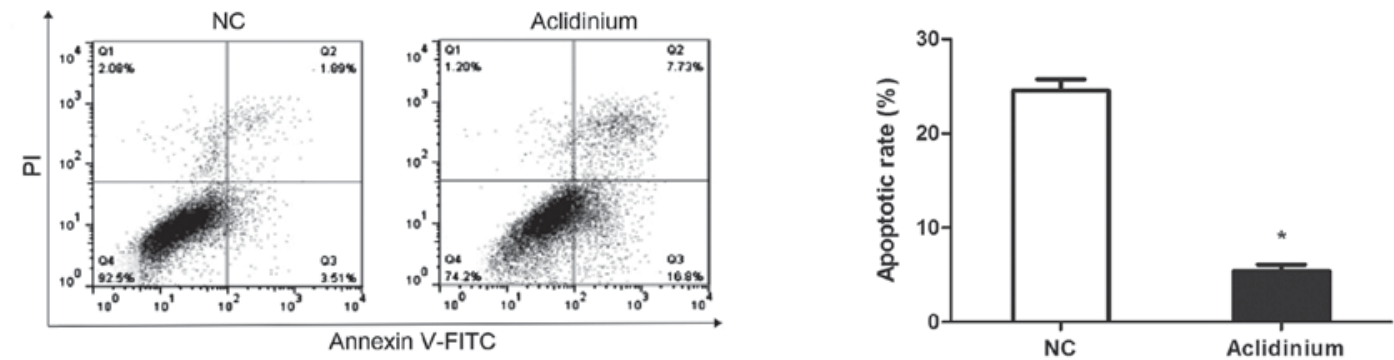

B
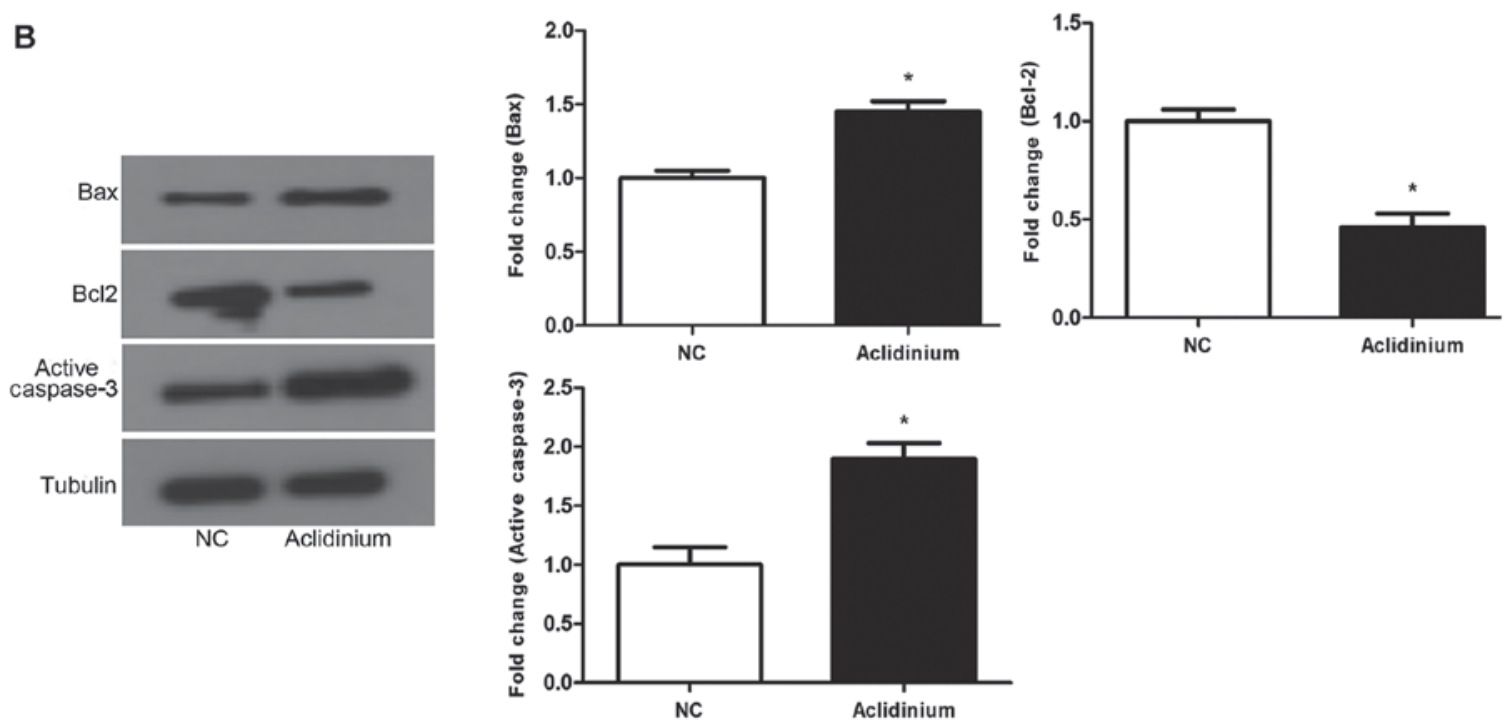

Figure 3. Aclidinium promotes apoptosis of ovarian cancer SKOV3 cells. (A) Cell apoptosis was analyzed by flow cytometry. (B) Protein expression levels were assessed using western blotting. Data are exhibited as mean \pm SD. " $\mathrm{P}<0.05$, in contrast with NC group.

the OD value was significantly decreased compared to the $\mathrm{NC}$ group 48 and $72 \mathrm{~h}$ after administration (Fig. $1 ; \mathrm{P}<0.05$ ). These results suggested that the proliferation abilities of SKOV3 cells decreased evidently after treatment with aclidinium.

Aclidinium inhibits metastasis and invasion of OC SKOV3 cells. Transwell metastasis and invasion were used to measure the potential effect of aclidinium on SKOV3 cells migration and invasion. As shown in Fig. 2A, the numbers of invaded cells after aclidinium treatment were markedly decreased $(15 \pm 2)$ compared with the NC groups $(50 \pm 4) \quad(\mathrm{P}<0.05)$. Likewise, as shown in Fig. 2B, the metastasis ability in the aclidinium treatment group was also inhibited compared with the NC group $(80 \pm 5<115 \pm 8)(\mathrm{P}<0.05)$. These results showed 

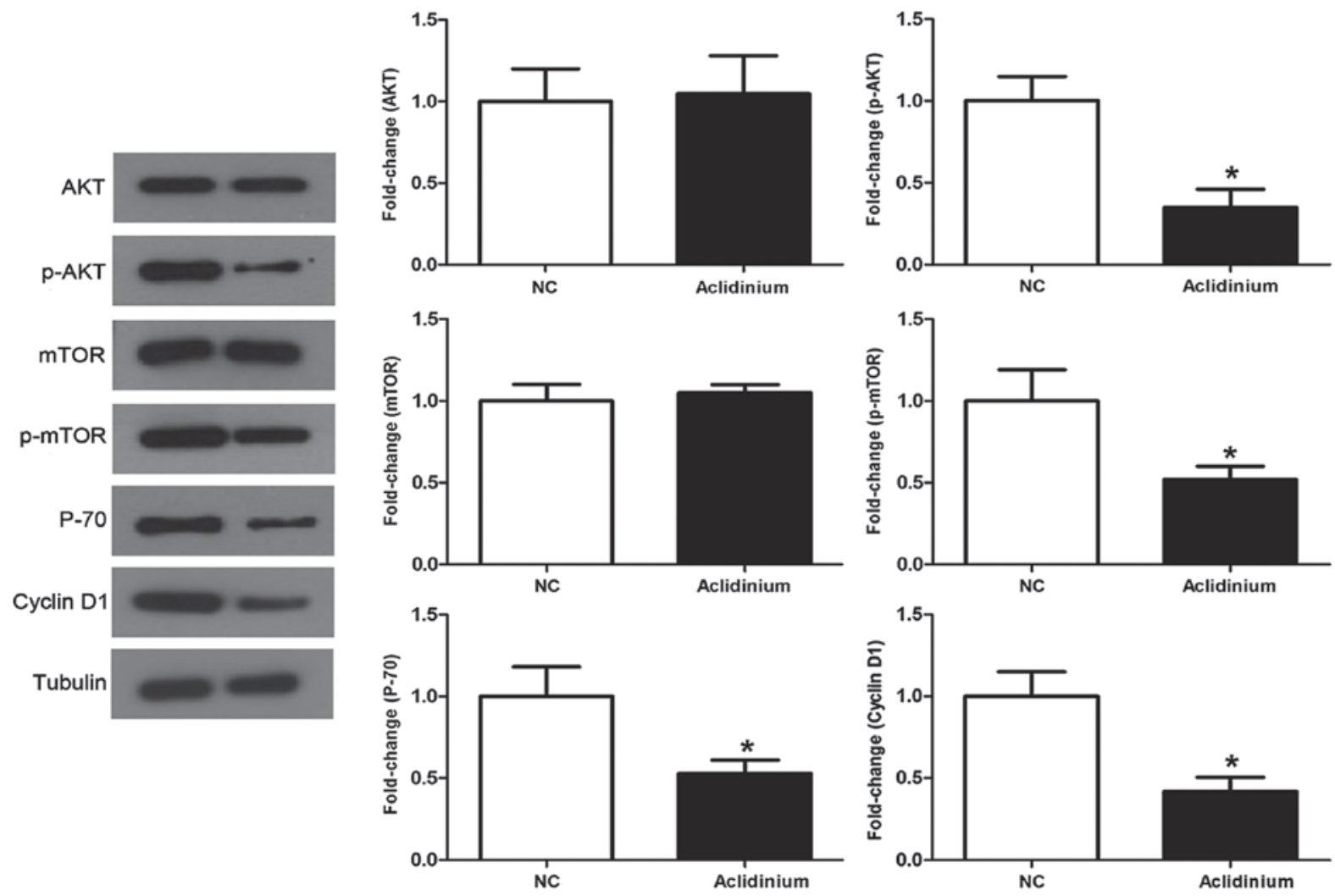

Figure 4. Aclidinium downregulates PI3K/AKT/mTOR signaling pathway. The ability was measured by using western blotting. Data are expressed as mean $\pm \mathrm{SD}$. ${ }^{*} \mathrm{P}<0.05$, in comparison with $\mathrm{NC}$ group.

that aclidinium could inhibit metastasis and invasion of $\mathrm{OC}$ SKOV3 cells.

Aclidinium promotes apoptosis of OC SKOV3 cells. To examine whether aclidinium influences SKOV3 cell apoptosis, flow cytometry assay with staining Annexin-V-FITC/PI was applied to test the SKOV3 cell apoptotic ratio. Results discovered that cell apoptotic rate in aclidinium group was significantly increased compared with NC groups $(24.53>5.4 \%)$ (Fig. $3 \mathrm{~A}$; $\mathrm{P}<0.05)$. Western blotting was used to examine the proteins closely related with apoptosis. Results revealed that after treatment with aclidinium, the expression of the anti-apoptotic protein, $\mathrm{Bcl}-2$, was decreased while the level of pro-apoptotic protein Bax and active-caspase-3 were increased significantly (Fig. 3B; $\mathrm{P}<0.05$ ). These results showed that aclidinium could effectively promote apoptosis of OC SKOV3 cells.

Aclidinium induces inhibition of the activation of PI3K/AKT/ mTOR signaling pathway in OC SKOV3 cells. It has been demonstrated that PI3K/AKT signaling pathway plays a vital role in numerous tumors (13). Thus, to assess the role of aclidinium in the inhibition of PI3K/AKT signaling, we detected a series of specific key proteins with this vital pathway. The results in Fig. 4 show that administration of SKOV3 cells with aclidinium results in dramatic decrease in the phosphorylation levels of AKT and mTOR, while no obvious changes were observed in the total AKT and mTOR level. Besides, aclidinium administration attenuated activity of PI3K/AKT/mTOR signaling downstream proteins such as P70 and cyclin D1 related to cell growth. Together, these results showed that aclidinium could inhibit activation of $\mathrm{PI} 3 \mathrm{~K} / \mathrm{AKT} / \mathrm{mTOR}$ signaling pathway.

\section{Discussion}

In this investigation, we explored the potential antitumor effect of aclidinium in OC. Before the formal experiments, the antiproliferative effects of various concentrations of aclidinium, including 2, 5, 10 and $20 \mu \mathrm{M}$, were evaluated. The results showed that when the concentration of aclidinium was up to $20 \mu \mathrm{M}$, the cell viability was inhibited significantly. So in the following experiments, $20 \mu \mathrm{M}$ aclidinium was used. We found aclidinium was able to inhibit SKOV3 cell proliferation, migration and invasion while induced apoptosis of SKOV3 cells. Furthermore, it revealed that the above antitumorigenic potent effects of aclidinium may be regulated by inhibition of the $\mathrm{PI} 3 \mathrm{~K} / \mathrm{AKT} / \mathrm{mTOR}$ signaling pathway.

It has been demonstrated that aclidinium is muscarinic M3 antagonist drug, and may help chronic obstructive pulmonary disease (COPD) (14). Nevertheless, with incidence of various cancers and advancement of abundant research, muscarinic antagonist drug was considered as an antitumor agent in several cancers. Studies reported by Fritz et al (15) and Mayerhofer and Kunz (16) have suggested that a new cholinergic autocrine loop was expressed in normal ovary, implying muscarinic antagonists is likely to control OC. There are more studies showing that muscarinic antagonist drug could inhibit tumor cell proliferation and migration such as lung carcinoma (17), urothelial bladder cancer (18) and colon cancer (19), and our results were consistent with these 
studies. Furthermore, the report depicted that muscarinic antagonist drug inhibited cell growth in vitro, and in transplanted nude mice decreased levels of MAPK phosphorylation was observed (20). It is well established that the mAChRs harbor five genetically different subtypes: M1-5. Among these mAChRs, M1, M3, and M5 are combined with the Gq type of $\mathrm{G}$ proteins which irritate phospholipase $\mathrm{C}$ to initiate the phosphatidylinositol triphosphate-signaling cascade (17). There is research that $[3 \mathrm{H}]$ quinuclidinyl benzilate $(\mathrm{QNB})$, emerged as radioligand, was used to examine muscarinic cholinergic receptor sites in separated plasma membrane fractions from human OC, the final results showed that the emergence of muscarinic receptors in ovarian adenocarcinoma by bonding profile were optimum coherent with M3 receptors (21). In our study, the results showed aclidinium could inhibit SKOV3 cell proliferation, migration and invasion as well as promote apoptosis which were consistent with the above point of view. Collectively, all the results indicated that aclidinium (a muscarinic M3 antagonist) acts on antiproliferative and antimetastatic characteristics in $\mathrm{OC}$.

The PI3K/AKT/mTOR signaling is supposed to be a vital player in cancer proliferation, metastasis and carcinoge nesis (22). The activation of the PI3K/AKT/mTOR signaling pathway is of importance in OC tumorigenesis, chemotherapy resistance and progression $(23,24)$. PIK3 and AKT2 overexpression has been observed in OC $(25,26)$ and the signaling is emerging as an important and viable therapeutic target in OC (27). Importantly, cyclin D1 has been documented to affect OC cell growth $(28,29)$, and it is the indispensable downstream protein of $\mathrm{PI} 3 \mathrm{~K} / \mathrm{AKT} / \mathrm{mTOR}$ signaling. Consistent with this result, our finding revealed that key factors of signaling, p-AKT and p-mTOR were reduced after administration with aclidinium, downstream factors like cyclin D1 and P70 were also reduced by aclidinium treatment. Altogether, the above data indicated that aclidinium exerted potent prohibitory activity against SKOV3 cell proliferation, invasion, metastasis and this might be via mediating PI3K/AKT/mTOR pathway inactivation.

In conclusion, this study elucidated that aclidinium could inhibit SKOV3 cell proliferation, migration and invasion as well as promote apoptosis. Furthermore, these effects might be achieved by downregulating PI3K/AKT/mTOR signaling pathway. The above studies have provided experimental basis for the future development of clinical anticancer drugs. However, there still exist limitations in this subject. It is unclear if there are more signaling pathways mediating the functional role of aclidinium. These questions still require future studies.

\section{Acknowledgements}

Not applicable.

\section{Funding}

No funding was received.

\section{Availability of data and materials}

The datasets used and/or analyzed during the present study are available from the corresponding author on reasonable request.

\section{Authors' contributions}

YZ conceived the study and drafted the manuscript. JQ and WJW performed the experiments, analyzed the data and revised the manuscript. All authors read and approved the final manuscript.

\section{Ethics approval and consent to participate}

Not applicable.

\section{Patient consent for publication}

Not applicable.

\section{Competing interests}

The authors declare that they have no competing interests.

\section{References}

1. Minlikeeva AN, Freudenheim JL, Cannioto RA, Szender JB, Eng KH, Modugno F, Ness RB, LaMonte MJ, Friel G, Segal BH, et al; Australian Ovarian Cancer Study Group; Ovarian Cancer Association Consortium: History of hypertension, heart disease, and diabetes and ovarian cancer patient survival: Evidence from the ovarian cancer association consortium. Cancer Causes Control 28: 469-486, 2017.

2. Schorge JO, Clark RM, Lee SI and Penson RT: Primary debulking surgery for advanced ovarian cancer: Are you a believer or a dissenter? Gynecol Oncol 135: 595-605, 2014.

3. Shi T, Wang P, Xie C, Yin S, Shi D, Wei C, Tang W, Jiang R, Cheng X, Wei Q, et al: BRCA1 and BRCA2 mutations in ovarian cancer patients from China: Ethnic-related mutations in BRCA1 associated with an increased risk of ovarian cancer. Int J Cancer 140: 2051-2059, 2017.

4. Vogel TJ, Goodman MT, Li AJ and Jeon CY: Statin treatment is associated with survival in a nationally representative population of elderly women with epithelial ovarian cancer. Gynecol Oncol 146: 340-345, 2017.

5. Armstrong DK, Bundy B, Wenzel L, Huang HQ, Baergen R, Lele S, Copeland LJ, Walker JL and Burger RA; Gynecologic Oncology Group: Intraperitoneal cisplatin and paclitaxel in ovarian cancer. N Engl J Med 354: 34-43, 2006.

6. Patel S, Kumar L and Singh N: Metformin and epithelial ovarian cancer therapeutics. Cell Oncol (Dordr) 38: 365-375, 2015.

7. Spindel ER: Muscarinic receptor agonists and antagonists: Effects on cancer. Handb Exp Pharmacol 208: 451-468, 2012.

8. Hua N, Wei X, Liu X, Ma X, He X, Zhuo R, Zhao Z, Wang L, Yan H, Zhong B, et al: A novel muscarinic antagonist R2HBJJ inhibits non-small cell lung cancer cell growth and arrests the cell cycle in G0/G1. PLoS One 7: e53170, 2012.

9. Oppitz M, Möbus V, Brock S and Drews U: Muscarinic receptors in cell lines from ovarian carcinoma: Negative correlation with survival of patients. Gynecol Oncol 85: 159-164, 2002.

10. Shah N, Khurana S, Cheng K and Raufman JP: Muscarinic receptors and ligands in cancer. Am J Physiol Cell Physiol 296: C221-C232, 2009.

11. Song P, Sekhon HS, Lu A, Arredondo J, Sauer D, Gravett C, Mark GP, Grando SA and Spindel ER: M3 muscarinic receptor antagonists inhibit small cell lung carcinoma growth and mitogen-activated protein kinase phosphorylation induced by acetylcholine secretion. Cancer Res 67: 3936-3944, 2007.

12. Ni H, Soe Z and Moe S: Aclidinium bromide for stable chronic obstructive pulmonary disease. Cochrane Database Syst Rev 19: CD010509, 2014

13. Martini M, De Santis MC, Braccini L, Gulluni F and Hirsch E: PI3K/AKT signaling pathway and cancer: An updated review. Ann Med 46: 372-383, 2014.

14. Reid DJ and Carlson AA: Clinical use of aclidinium in patients with COPD. Int J Chron Obstruct Pulmon Dis 9: 369-379, 2014. 
15. Fritz S, Wessler I, Breitling R, Rossmanith W, Ojeda SR, Dissen GA, Amsterdam A and Mayerhofer A: Expression of muscarinic receptor types in the primate ovary and evidence for nonneuronal acetylcholine synthesis. J Clin Endocrinol Metab 86: 349-354, 2001.

16. Mayerhofer A and Kunz L: A non-neuronal cholinergic system of the ovarian follicle. Ann Anat 187: 521-528, 2005.

17. Ami N, Koga K, Fushiki H, Ueno Y, Ogino Y and Ohta H: Selective M3 muscarinic receptor antagonist inhibits small-cel lung carcinoma growth in a mouse orthotopic xenograft model. J Pharmacol Sci 116: 81-88, 2011.

18. Pacini L, De Falco E, Di Bari M, Coccia A, Siciliano C, Ponti D, Pastore AL, Petrozza V, Carbone A, Tata AM, et al: M2 muscarinic receptors inhibit cell proliferation and migration in urothelial bladder cancer cells. Cancer Biol Ther 15: 1489-1498, 2014.

19. Park YS and Cho NJ: Enhanced proliferation of SNU-407 human colon cancer cells by muscarinic acetylcholine receptors. BMB Rep 41: 803-807, 2008.

20. Russo P, Del Bufalo A, Milic M, Salinaro G, Fini M and Cesario A: Cholinergic receptors as target for cancer therapy in a systems medicine perspective. Curr Mol Med 14: 1126-1138, 2014.

21. Batra S, Popper LD and Iosif CS: Characterisation of muscarinic cholinergic receptors in human ovaries, ovarian tumours and tumour cell lines. Eur J Cancer 29A: 1302-1306, 1993.

22. Dobbin ZC and Landen CN: The importance of the $\mathrm{PI} 3 \mathrm{~K} / \mathrm{AKT} / \mathrm{MTOR}$ pathway in the progression of ovarian cancer. Int J Mol Sci 14: 8213-8227, 2013.
23. Mabuchi S, Kuroda H, Takahashi $\mathrm{R}$ and Sasano T: The $\mathrm{PI} 3 \mathrm{~K} / \mathrm{AKT} / \mathrm{mTOR}$ pathway as a therapeutic target in ovarian cancer. Gynecol Oncol 137: 173-179, 2015.

24. Cazzola M: Aclidinium bromide, a novel long-acting muscarinic M3 antagonist for the treatment of COPD. Curr Opin Investig Drugs 10: 482-490, 2009.

25. Shayesteh L, Lu Y, Kuo WL, Baldocchi R, Godfrey T, Collins C, Pinkel D, Powell B, Mills GB and Gray JW: PIK3CA is implicated as an oncogene in ovarian cancer. Nat Genet 21: 99-102, 1999.

26. Cheng JQ, Ruggeri B, Klein WM, Sonoda G, Altomare DA, Watson DK and Testa JR: Amplification of AKT2 in human pancreatic cells and inhibition of AKT2 expression and tumorigenicity by antisense RNA. Proc Natl Acad Sci USA 93: 3636-3641, 1996.

27. Lau MT and Leung PC: The PI3K/Akt/mTOR signaling pathway mediates insulin-like growth factor 1-induced E-cadherin down-regulation and cell proliferation in ovarian cancer cells. Cancer Lett 326: 191-198, 2012.

28. Xia B, Yang S, Liu T and Lou G: miR-211 suppresses epithelial ovarian cancer proliferation and cell-cycle progression by targeting Cyclin D1 and CDK6. Mol Cancer 14: 57, 2015.

29. Wu W, Slomovitz BM, Soliman PT, Schmeler KM, Celestino J, Milam MR and Lu KH: Correlation of cyclin D1 and cyclin D3 overexpression with the loss of PTEN expression in endometrial carcinoma. Int J Gynecol Cancer 16: 1668-1672, 2006.

(c) (i) $(9$ This work is licensed under a Creative Commons CYY NO NO Attribution-NonCommercial-NoDerivatives 4.0 International (CC BY-NC-ND 4.0) License. 